\title{
MILHETO NA AGRICULTURA FAMILIAR: SUPLEMENTAÇÃO ALIMENTAR NO PERÍODO SECO NO ASSENTAMENTO BELO HORIZONTE - PA
}

\author{
Vanessa Kamila da Silva Pereira ${ }^{1}$; Luis Moreira de Araújo Junior ${ }^{2}$; Alzira Gabriela da \\ Silva $^{3}$; Laura Angélica Ferreira ${ }^{4}$.
}

\author{
${ }^{1}$ Discente da Faculdade de Ciências Agrárias de Marabá da Universidade Federal do Pará, \\ vanessakamila@yahoo.com.br; ${ }^{2}$ Discente da Faculdade de Ciências Agrárias de Marabá da UFPA; ${ }^{3}$ M.Sc. Docente da \\ Faculdade de Ciências Agrárias de Marabá da UFPA; ${ }^{4}$ D.Sc. Docente do Núcleo de Ciências Agrárias e \\ Desenvolvimento Rural da UFPA.
}

\begin{abstract}
RESUMO: Com o propósito de difundir o milheto (Pennisetum glaucum (L.) R. Brown) para ser fornecido aos animais, objetivou-se avaliar o desenvolvimento inicial desta gramínea submetida à adubação orgânica e inorgânica, caracterizar o nível de aceitação dos agricultores que optaram em participar da ação-teste com milheto. O estudo foi conduzido no Projeto de Assentamento Belo Horizonte, em São Domingos do Araguaia, Pará. Foram implantados sete parcelas (A, B, C, D, E, F, $\mathrm{G})$, porém somente dois módulos receberam acompanhamento agronômico (A e B). Os tratamentos foram sementes tratadas com adubação orgânica (TO); sementes tratadas com adubação nitrogenada (TI); sementes não tratadas com adubação orgânica (NTO) e sementes não tratadas com adubação nitrogenada (NTI). O delineamento experimental foi inteiramente casualizado com arranjo fatorial 2 $\mathrm{X} 2$ com seis repetições. Os parâmetros avaliados no desenvolvimento inicial foram o comprimento (parte aérea e raiz) e a estatura (parte aérea) da planta, os quais foram mensurados em Março de 2009. As analises estatísticas foram realizadas pelo software SAS (2007). Foram realizadas entrevistas com o auxílio de um questionário para caracterizar o nível de aceitação do milheto. Quanto ao comprimento do milheto foi verificado diferença estatística $(\mathrm{P}<0,05)$ apenas nas sementes tratadas para as plantas submetidas à adubação com sulfato de amônio $(26,37 \mathrm{~cm})$. Na estatura verificou-se que tantos as sementes tratadas como as não tratadas apresentaram diferença estatística $(\mathrm{P}<0,05)$ entre as fontes de adubação, com maior média $(20,52 \mathrm{~cm})$ para as plantas adubadas com sulfato de amônio. Houve uma boa receptividade dos agricultores diante das ações-teste.
\end{abstract}

PALAVRAS-CHAVE: bovinos leiteiros, Pennisetum glaucum, volumoso.

\section{PEARL MILLET IN THE FAMILY FARM: DRY FOOD SUPPLEMENTATION DURING THE SETTLEMENT BH - PA}

\begin{abstract}
In order to spread the millet (Pennisetum glaucum (L.) R. Brown) to be supplied to the animals, aimed to evaluate the initial development of this grass subjected to organic and inorganic fertilizer, to characterize the level of acceptance by farmers who chose to participate in the action-test with millet. The study was conducted in Belo Horizonte Settlement Project in São Domingos do Araguaia, Pará seven plots were established (A, B, C, D, E, F, G), but only two modules were followed agronomic (A and $\mathrm{B}$ ). The treatments were seeds treated with organic manure (TO), seeds treated with nitrogen fertilizer (IT); seeds not treated with organic manure (NOT) and untreated seeds with nitrogen (NIT). The experimental design was completely randomized design with $2 \times 2$ factorial arrangement with six replicates. The parameters were evaluated on initial length (shoot and root) and height (shoot) plant, which were measured in March 2009. The statistical analysis were performed by SAS softwer (2007). Interviews were conducted with the aid of a questionnaire to characterize the level of acceptance of pearl millet. As to the length of millet was found statistical difference $(\mathrm{P}<0.05)$ only treated seed for plants subjected to fertilization with ammonium sulfate $(26.37 \mathrm{~cm})$. In height it was found that many treated seeds as
\end{abstract}


untreated differ significantly $(\mathrm{P}<0.05)$ among nutrient sources, with the highest average $(20.52 \mathrm{~cm})$ for the plants fertilized with ammonium sulfate. There was a good response from farmers in the face of stock-test.

KEY-WORDS: dairy cattle, Pennisetum glaucum, forage.

\section{INTRODUÇÃO}

Na região Sudeste do Estado do Pará há uma grande concentração de propriedades familiares, alocadas principalmente nos diversos Projetos de Assentamentos (P.A), que de acordo com o Instituto Nacional de Colonização e Reforma Agrária (INCRA) totalizavam 176 P. A. com aproximadamente 21.914 famílias (BRASIL, 2009).

No P.A Belo Horizonte um dos grandes problemas enfrentados pelos agricultores é o déficit alimentar, principalmente no período seco do ano. O rebanho leiteiro mantido exclusivamente à pasto necessita de forragem de qualidade e em quantidade suficiente para suprir suas necessidades nutricionais.

Como alternativa para atenuar esse problema, os agricultores vêm adotando práticas como introdução de gramíneas mais produtivas, além de técnicas de conservacão dessas forrageiras como ocorrem no processo de silagem e fenação. Nesse contexto, destaca-se a utilização do milheto (Pennisetum glaucum (L.) R. Brown) forrageiro como alternativa de volumoso para o período seco, pois esta espécie possui boa adaptação à condições adversas, excelente valor nutritivo, podendo atingir em torno de $24 \%$ de proteína bruta, sob pastejo, com boa palatabilidade e digestibilidade (60 a 78\%)
(KICHEL et al., 1999). Além de ser considerada uma espécie promissora a ser utilizada como alternativa alimentar pelos agricultores familiares (MOREIRA et al., 2003).

Face ao exposto, foi conduzido estudo cujos objetivos foram: difundir o milheto forrageiro no PA Belo Horizonte (PABH) para que seja fornecido aos animais no período seco do ano; avaliar o desenvolvimento inicial desta gramínea submetida a adubação orgânica e inorgânica em estabelecimentos familiares no P. A. e ainda caracterizar o nível de aceitação dos agricultores que optaram em participar da ação-teste com milheto.

\section{MATERIAL E MÉTODOS}

O trabalho foi conduzido no PA Belo Horizonte I situado no km 30 da BR-153, no município de São Domingos do Araguaia, aproximadamente a $80 \mathrm{~km}$ do município de Marabá. O tipo de solo predominante é o Latossolo vermelho amarelo Distrófico com textura média e Podzólico vermelho amarelo com textura argilo-arenosa com $60 \%$ de argila e $40 \%$ de areia (FIGUEREIDO, 2001).

Este trabalho foi desenvolvido no âmbito do projeto de pesquisa "Promover Inovações para o Fortalecimento da Agricultura 
Familiar nos Assentamentos do Sudeste do Pará" financiado pelo Conselho Nacional de Desenvolvimento Científico e Tecnológico (CNPq). O trabalho foi conduzido com a utilização de metodologias de pesquisa-ação e de pesquisa participativa para a construção de inovações (FRAPPAT et al., 2005) com o propósito de construir inovações em parcerias com agricultores (CHIA, DUGUÉ E SAKHO-JIMBIRA, 2006). Considera-se como ação-teste, quando guiado por um facilitador, os agricultores realizam um pequeno ensaio teste, em parcelas pequenas, as quais podem ter diferentes tratamentos (CIAT, 1993).

As atividades de difusão do milheto iniciaram em novembro de 2008, com uma reunião em que participaram 30 famílias, onde foram apresentadas alternativas para o problema de pastagens e alimentação das vacas leiteiras. No dia 18 de fevereiro de 2009, foi realizada uma formação sobre a gramínea milheto, abordando as características agronômicas, vantagens, forma de plantio e fornecimento ao gado.

Sete famílias optaram pelo milheto, as quais implantaram parcelas com a gramínea (A, B, C, D, E, F e G) em seus estabelecimentos para que pudessem conhecer o crescimento e desenvolvimento da espécie nas condições locais. De acordo com o que prevê a metodologia participativa, o grupo de agricultores que optarem por essa alternativa escolheria os lotes onde seriam implantadas as parcelas demonstrativas. Desta forma, das sete parcelas implantadas, somente duas receberam acompanhamento técnico no plantio do milheto - parcelas A e B.

As sementes dos híbridos de milheto utilizadas foram não tratada ADR 7010 (peneira 2,0) e semente tratada LABH 070730. Para o preparo do solo foram realizados roço e capina.

O plantio manual foi realizado em sucos nas parcelas "A" e "B", com áreas de $10 \mathrm{~m}^{2}$ cada, divididos em quatro parcelas. As sementes foram distribuídas em seis fileiras de 5 metros lineares, espaçadas em 0,4 $\mathrm{m}$ com densidade de 20 sementes puras viáveis (SPV) por metro linear.

Após oito dias do plantio, foi realizada uma visita nas áreas para verificar problemas de germinação, a ocorrência de ataque de insetos e animais e o desbaste.

Efetuou-se na parcela “A” uma adubação de cobertura com adubo orgânico de esterco bovino curtido e adubo inorgânico sob a forma de sulfato de amônio ( $80 \mathrm{~kg} \cdot \mathrm{ha}^{-1}$ de N) lançado em superfície três dias após a germinação. Os tratamentos foram: sementes tratadas com adubação orgânica (TO); sementes tratadas com adubação nitrogenada (TI); sementes não tratadas com adubação orgânica (NTO) e sementes não tratadas com adubação nitrogenada (NTI). O delineamento experimental foi inteiramente casualizado com arranjo fatorial $2 \times 2$ com seis repetições.

Os parâmetros avaliados no desenvolvimento inicial da gramínea foram o 
comprimento (parte aérea e raiz) e a estatura (parte aérea) da planta, mensurados 15, 20 e 25 dias depois da germinação. Para isso foram coletadas 15 plantas de cada linha. As análises estatísticas foram realizadas através do programa computacional Statistical Analysis System (SAS, 2002) utilizando-se o procedimento PROC GLM, seguido do teste de Duncan e as médias foram comparadas a um nível de 5\% de significância.

Para saber a aceitação das sete famílias foram realizadas entrevistas com o auxílio de um questionário com perguntas abertas e fechadas. Os dados coletados foram analisados com auxílio de planilha do Microsoft Office Excel.

\section{RESULTADOS E DISCUSSÃO}

No módulo “A”, a germinação ocorreu três dias após o plantio e teve boa emergência das sementes tratadas e não tratadas. $\mathrm{O}$ agricultor observou a presença de pragas, tais como cigarrinhas, grilos e besouros, as quais causaram injúrias em suas estruturas.

$\mathrm{Na}$ parcela "B" foram realizadas duas tentativas de implantação dessa gramínea. $\mathrm{Na}$ primeira tentativa o milheto não germinou devido ao ataque de galinhas criadas soltas, as quais comeram as sementes. $\mathrm{Na}$ segunda tentativa o milheto foi implantado próximo a uma área de mata, contudo houve ataque de formigas. Sugere-se que as formigas foram atraídas para a área semeada, pelo alto teor de proteína bruta presente nas sementes de milheto.

A implantação das sementes de milheto nas demais parcelas (C, D, E, F e G) ocorreu de forma correta, visto que, não foi identificado nenhum problema quanto à germinação. Nas parcelas com alta densidade de plantio foi realizado o desbate. Ao final do ciclo vegetativo do milheto, com o intuito de aproveitar a biomassa vegetal produzida nas parcelas os agricultores cortaram a forragem e forneceram ao rebanho. Os animais demonstraram boa aceitabilidade ao volumoso.

Verificou-se que houve diferenças significativas entre as sementes tratadas e não tratadas com valores médios de $24,82 \mathrm{~cm}$ e $27,74 \mathrm{~cm}$, respectivamente (Tabela 1). Esse resultado indica que as sementes não tratadas tiveram maior adaptação às condições edafoclimáticas locais.

Tabela 1. Médias do comprimento $(\mathrm{cm})$ das plantas submetidas às fontes de adubação.

\begin{tabular}{llll}
\hline Sementes & Orgânico & Adubo & Média \\
& $23,28 \mathrm{~b}$ & Sulfato de Amônio & \\
\hline Tratadas & $26,98 \mathrm{~b}$ & $26,37 \mathrm{a}$ & $24,82 \mathrm{~B}$ \\
Não tratadas & $25,13 \mathrm{~b}$ & $28,50 \mathrm{~b}$ & $27,74 \mathrm{~A}$ \\
\hline Média & $27,44 \mathrm{a}$ & \\
\hline Letras minúsculas diferentes indicam diferença estatística $(\mathrm{P}<0,05)$, pelo teste de Duncan. Letras \\
maiúsculas diferentes na coluna indicam diferença estatística $(\mathrm{P}<0,05)$, pelo teste de Duncan.
\end{tabular}


Com relação às fontes de nutrientes, observou-se que as sementes tratadas diferiram $(\mathrm{P}<0,05)$ com maior comprimento determinado para a fonte nitrogenada inorgânica $(26,37 \mathrm{~cm})$, tal fato pode estar relacionado com os teores relativamente pobres de nitrogênio $(\mathrm{N})$ no esterco bovino, enquanto que, o sulfato de amônio apresenta aproximadamente $21 \%$ de N. As sementes não tratadas não apresentaram diferença $(\mathrm{P}<0,05)$ no comprimento entre as fontes aplicadas.

No parâmetro estatura das plantas também houve diferença significativa entre as sementes tratadas e não tratadas com valores médios de $17,54 \mathrm{~cm}$ e $20,99 \mathrm{~cm}$, respectivamente, assim como entre as fontes (Tabela 2), visto que, mesmo sendo uma planta adaptada à baixa fertilidade do solo, o milheto apresenta alta resposta de produção para solos adubados.

Tabela 2. Médias da estatura (cm) das plantas submetidas às fontes de adubação.

\begin{tabular}{llll}
\hline Sementes & & Adubo & Média \\
& Orgânico & Sulfato de Amônio & \\
\hline Tratadas & $16,38 \mathrm{~b}$ & $18,69 \mathrm{a}$ & $17,54 \mathrm{~B}$ \\
Não tratadas & $19,66 \mathrm{~b}$ & $22,34 \mathrm{a}$ & $20,99 \mathrm{~A}$ \\
\hline Média & $18,02 \mathrm{~b}$ & $20,52 \mathrm{a}$ & \\
\hline
\end{tabular}

Letras minúsculas diferentes indicam diferença estatística $(\mathrm{P}<0,05)$, pelo teste de Duncan. Letras maiúsculas diferentes na coluna indicam diferença estatística $(\mathrm{P}<0,05)$, pelo teste de Duncan.

A estatura das plantas desenvolveu-se melhor quando foi utilizada a fonte inorgânica comparados com a fonte orgânica, onde os valores médios foram de $20,52 \mathrm{~cm}$ e 18,02 $\mathrm{cm}$, visto que, a alta concentração de $\mathrm{N}$, propiciou maior crescimento da parte aérea do milheto forrageiro.

Através dos questionamentos realizados verificou-se que todos os agricultores (100\%) demonstraram interesse em continuar cultivando o milheto e com o fornecimento da forragem ao rebanho visam aumentar a produtividade leiteira. No processo de implantação do milheto $71,42 \%$ dos agricultores seguiram as recomendações da equipe e $28,57 \%$ optaram por utilizar seus conhecimentos e realizaram o plantio semelhante ao do milho (Zea mays L.). Os entrevistados $(71,42 \%)$ afirmaram ter condições de replicar a tecnologia sem acompanhamento técnico.

Portanto, quanto à receptividade dos agricultores diante das ações-testes observouse que foi unânime a aceitação e o interesse em fazer o plantio do milheto forrageiro. 


\section{CONCLUSÃO}

O sulfato de amônio apresentou melhores resultados no desenvolvimento da planta forrageira, sendo sugerida a sua utilização no manejo de banco forrageiro com sementes não tratadas nessas condições.

A ação-teste com milheto forrageiro foi bem aceita pelos agricultores que acompanharam e implantaram as parcelas de banco forrageiro, cuja atividade predominante dos mesmos é a pecuária leiteira.

\section{REFERÊNCIAS}

BRASIL. Instituto Nacional de Colonização e Reforma Agrária - INCRA. Superintendência Regional do Sul do Pará - SR(27). Ordem de Serviço/SR-(27)G/N 01-11, de 02 de janeiro de 2009. Diário Oficial da União, Brasília, 20 de outubro de 2006; 264 p.

CENTRO INTERNACIONAL DE AGRICULTURA TROPICAL. Cartillas para CIAL (Comités de Investigación Agrícola Local: O ensayo. Cali: CIAT/IPRA, 1993. $43 \mathrm{p}$.

CHIA E.; DUGUÉ P.; SAKHO-JIMBIRA S. Les exploitations agricoles familiales sontelles des institutions? In Agricultures, Montpellier, v. 15, n. 6, 2006, 498-505 p.

FIGUEIREDO, R. B.; WAMBERGUE, E.; COElho, E. M.; MORAES, J. R. Plano de Desenvolvimento Sustentável do Assentamento do Projeto de Assentamento Belo Horizonte. Marabá, PA: Copserviços. Junho, 2001. 135 p.
FRAPPAT, B.; DOCKES, A. C.; SOUQUEST, C.; LACOUR, C. Les attentes des éleveurs de bovins en matière de conseil. Actes des Rencontres recherches Ruminants, Paris, 2005, v. 1, n. 12, p. 69-72, 2005.

KICHEL, A. N.; MIRANDA, C $\mathrm{H} \mathrm{B} \mathrm{e}$ SILVA J M da. Mileto (Pennisetum americanum (L.) Leek) como planta forrageira. In: Workshop Internacional de Milheto, Brasília. Anais... Brasília, EMBRAPA, 1999. p. 97-103.

MOREIRA， L.B.; MALHEIROS, M.G.; CRUZ, B.B.G. Efeito da população de plantas sobre as características morfológicas e agronômicas de milheto pérola. Agronomia, v.37, n.1, p.05- 09, 2003.

SAS. Institute Inc. Statistical Analysis System user's guide. Version 9.13 ed. Cary: SAS Institute, USA, 2002. 